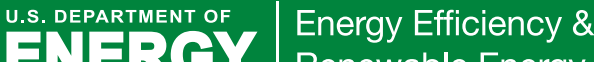 Renewable Energy \\ GEOTHERMAL TECHNOLOGIES PROGRAM
}

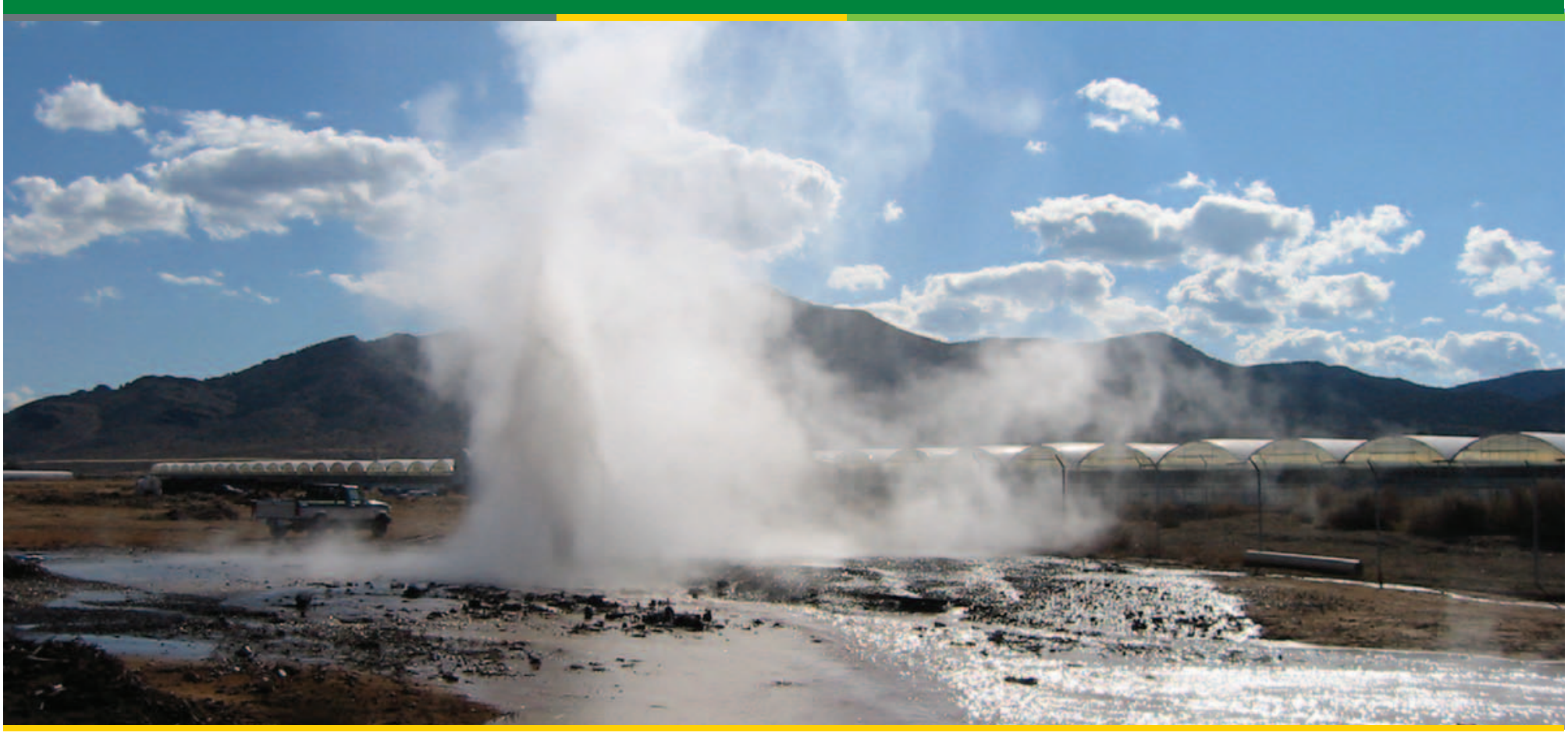

Photo by Robert Blackett, Utah Geological Survey, NREL/PIX 13995

\section{Harnessing the Earth's Heat}

Earth's massive amount of internal heat remains a virtually untapped energy resource that can provide reliable baseload power, meaning that geothermal technologies can produce electricity around the clock. Even better, geothermal energy is a clean, domestic resource that will help secure America's energy future.

Clean energy innovation resulting from research, development, and demonstration (RD\&D) activities is reducing the cost and improving the performance of geothermal technologies. The U.S. Department of Energy (DOE) partners with businesses, universities, and national laboratories to support the RD\&D that can capture the natural, emission-free energy beneath our feet. DOE's Geothermal Technologies Program is helping stimulate the growth of the industry, expanding geothermal energy use across the United States so that this clean energy resource can significantly contribute to America's future electricity generation.

\section{The Forefront of Geothermal Innovation}

The Geothermal Program is a leader in promoting the development of innovative technologies to find, access, and utilize the earth's heat throughout the United States for clean, renewable energy generation.

\section{Exploration Technologies}

Advancements in exploration technologies could substantially lower exploration risks and reduce upfront development costs. DOE aims to develop technologies that can identify approximately 30 gigawatts $(\mathrm{GW})$ of undiscovered geothermal resources in the western United States. Advanced exploration technologies include remote sensing and new geophysical survey methods.

\section{Enhanced Geothermal Systems}

Enhanced Geothermal Systems (EGS) are engineered reservoirs created from geothermal resources that lack fluid or permeable rock. DOE estimates that EGS technology could provide at least 100,000 megawatts (MW) of electricity within 50 years. EGS opens up many geothermal energy resources, enabling development in multiple geological environments at various depths. Applied across the United States, EGS can enhance the scale at which clean energy contributes to the U.S. energy portfolio.

\section{The Geothermal Program Supports:}

- Doubling electricity generated from clean energy sources by $2035-80 \%$ of electricity will come from clean energy sources like geothermal

- Expanding high-value research and development to drive down costs and enable clean energy deployment at scale

- Supporting education, training, and the job creation that will enable us to compete in a global economy and win the future

- Diversifying our domestic energy resources to secure America's long-term energy independence

- Promoting commercialization and facilitate technology transfer to industry. 


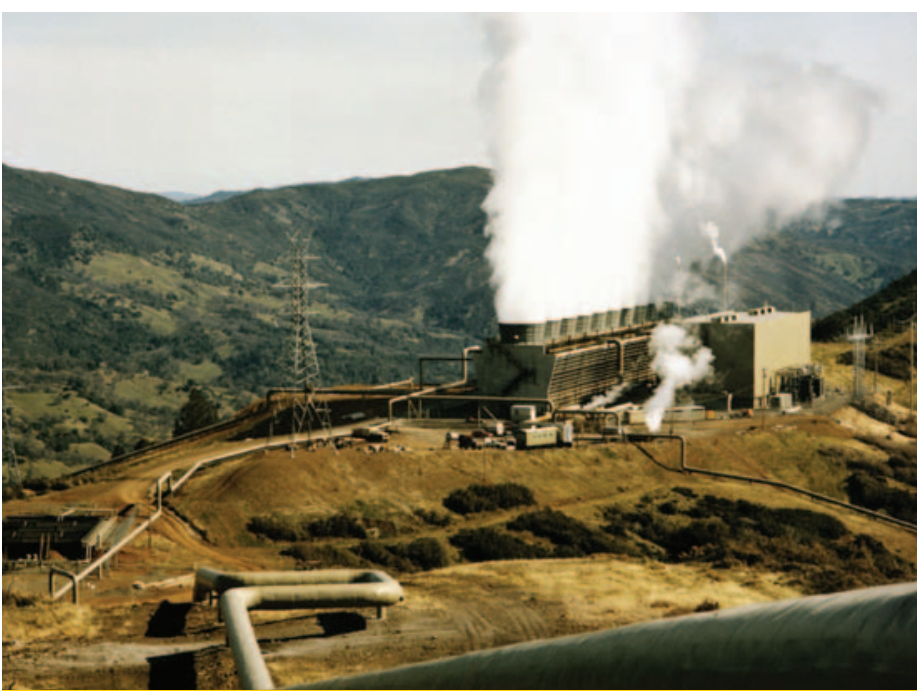

The Geysers in northern California is the world's largest producer of geothermal power. The dry-steam field has successfully produced power since the early 1960 s when Pacific Gas \& Electric installed the first 11-megawatt plant. The power plant uses NREL's condenser technology to increase operating efficiency. Photo from Pacific Gas \& Electric, NREL/PIX 00059

\section{Geothermal Resources}

\section{Geopressured}

Geopressured energy occurs in deep basins where fluids are under high pressure. The Geothermal Program is improving power generation turbines that can simultaneously harvest thermal, mechanical, and chemical energy from geopressured resources at a low cost.

\section{Low Temperature}

Low temperature (less than $150^{\circ} \mathrm{C}$ ) geothermal resources are not hot enough to be harnessed in conventional steampowered generators. With the development and adoption of new power conversion systems, these resources represent a significant opportunity for geothermal energy. Binary cycle systems have the capacity to convert lower temperature fluids into electrical power. Binary systems are modular in design and can be scaled to match a geothermal resource, potentially shortening construction lead-time and bringing resources online more quickly.

\section{Coproduction}

In the continental United States, an average of 10 barrels of water are produced with every barrel of oil. Currently treated as a waste product, much of this coproduced water from oil and gas wells is warm enough to generate electricity. This could provide additional value streams to extend the life of mature oil and gas fields, while adding a significant, clean source of electricity to America's energy portfolio.

\section{Key Activities}

\section{National Geothermal Data System}

The National Geothermal Data System (NGDS) is a distributed network of online databases and data sites linking geothermal data sets from across the United States. Assessing and categorizing the nation's geothermal resources and linking the data in a publicly accessible system helps researchers and industry reduce up-front risk and costs of geothermal development.

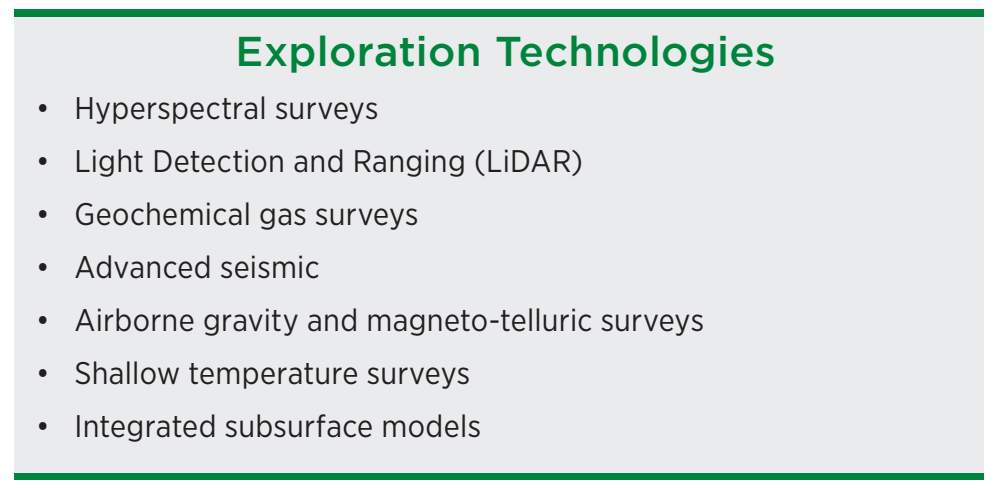

\section{Education}

The Geothermal Program is establishing education and workforce development projects to meet the needs of a growing geothermal industry through hands-on research and education, university curriculum development, fellowships and cosponsored internship programs.

\section{Funding Opportunity Announcements}

The Geothermal Program funds RD\&D and analytical activities through Funding Opportunity Announcements. Private companies, academic institutions, DOE's national laboratories, and others often compete for funding in project solicitations.

\section{Learn More}

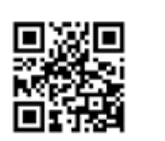

geothermal.energy.gov

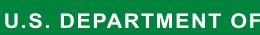
ENARCY

Energy Efficiency \&

Renewable Energy eere.energy.gov geothermal.energy.gov 